\title{
Information Systems Project Failure - Analysis of Causal Links using Interpretive Structural Modelling
}

D. Laurie Hughes ${ }^{\mathrm{a}}$, Yogesh K. Dwivedi ${ }^{\mathrm{a}}$, Nripendra P. Rana ${ }^{\mathrm{a}}$, Antonis C. Simintiras ${ }^{\mathrm{b}}$

${ }^{a}$ School of Management, Swansea University, Swansea, UK

${ }^{b}$ College of Business Administration, Gulf University for Science and Technology, Kuwait

Yogesh K. Dwivedi-y.k.dwivedi@swansea.ac.uk; ykdwivedi@gmail.com 


\begin{abstract}
The analysis of the root causes of information Systems (IS) project failure has been the subject of intense scrutiny for some time within industry and the academic community. Researchers have developed various models, notions of failure and categorizations to succinctly classify project failure into a set of key factors for organizations and project managers to focus on in their attempts to avoid failure. This study incorporates a technique titled: Interpretive Structural Modelling (ISM) as the methodology to formalize the relationships between the selected failure factors. This approach is positioned as a mechanism that can yield greater insights into the relationships between the factors surrounding project failure; thereby developing a better understanding of how these relationships can have a bearing on project outcomes. The findings identify key driving variables that are presented as having significant impact on the other factors within the model. A number of variables are also identified as being heavily dependent on other connected factors highlighting that a failure in one or more of these connected factors; is likely to result in a failure in one or more of the dependent factors unless timely steps are taken to address these key issues. This research details a number of practical implications for senior management and project managers as well as the academic community. These considerations form an underlying thread within this study as specific practice related implications are highlighted and discussed throughout the study.
\end{abstract}

Keywords - Interpretive Structural Modelling, failure factors, project management, information systems

\title{
1. Introduction
}

The track record of IS project delivery over the last four decades has demonstrated a litany of problems with success rates as low as 39 percent (Standish Group 2013) with resulting significant financial losses to the affected organizations (Dwivedi et al. 2013, 2015; Hughes et al. 2015). The recent findings of a National Audit Office (NAO) report into the failed Home Office e-borders scheme, highlight that despite spending $£ 830 \mathrm{~m}$ since April 2006, the project has failed to deliver its key benefits with border checks "remaining highly manual and inefficient", with the department forced to rely on "outdated IT systems" (BBC 2016a). The report goes on to state that the project will require a further $£ 275 \mathrm{~m}$ and will not be completed until March 2019 - eight years later than planned. Lorenzo - the abandoned National Programme for IT (NPfIT) - a £10bn IS project failure; was described by the Public Accounts Committee (PAC) as: "one of the most expensive failures in the history of the public sector..." Lorenzo was launched in 2002 to computerize the patient records of the 220 NHS trusts throughout the UK. The PAC highlighted that at the time of the investigation - over ten years from the start of the project; that not one of the trusts had a fully functioning care records system. The full costs for Lorenzo are estimated to reach at least $£ 12.2 \mathrm{bn}$ with a much-reduced scope where only 22 of the original 220 NHS trusts will be included. The UK government has recently announced a $£ 1$ bn technology fund to help the NHS move to a paperless structure by 2018. However, in the absence of a step change in approach to the establishment and management of public sector IS projects, it is not clear that this $£ 1$ bn will be spent wisely.

The literature has identified a never-ending pattern of IS project failure, especially large public sector project failure where organizations seem unable to learn the lessons of failure and apply this to new projects. These points and the wider aspects of the IS failure literature highlight the cold hard facts that many organizations seem unable to learn the lessons of failure, highlighting a pattern of repeating the same mistakes again and again (Ewusi-Mensah and Przasnyski 1995; Lyytinen and Robey 1999). What is clear is that although there is some evidence that the IS failure trend is improving with success rates identified as being $10 \%$ higher in recent studies when compared to those in 2004 (Standish Group 2013), we need to see a step 
change in our understanding and analysis of the causes of project failure and to identify early warning signs earlier in the lifecycle to mitigate the full impact of large IS project failure.

The reasons for the high rates of failure in this genre of project are many and varied (AlAhmad and Al-Fagih 2009; Dwivedi et al. 2015; Flowers 1997; Hughes et al. 2015; Lyytinen and Hirschheim 1987; Pinto and Mantel 1990) with no clear pattern of failure and identification of a single root cause. Organizations have experienced catastrophic outcomes from IS failure (Avison and Wilson 2002; Brown and Jones 1998; Gauld 2007; McGrath 2002; Mitev 1996; Pan et al. 2008) resulting in abandoned projects, huge financial loss for the organizations concerned and in some cases - loss of life directly attributed to the failure of the project (Beynon-Davies 1995). What is surprising looking back over a pattern of failure that has spanned over four decades; is the inability of organizations to learn the lessons of failure (Standish Group 2013) and how substantial detailed academic research has failed to have any substantial impact on project outcomes (Hughes et al. 2015). The analysis of IS project failure, even those of more recent projects, does not yield any new substantive failure factors or root causes. Although the order or ratio of the types of failure may change over time, it seems that IS projects fail now for basically the same reasons that they have always done (Lyytinen and Robey 1999; Standish Group 2013). This is a somewhat startling fact given the increased levels of professionalism within industry and the greater emphasis on methods and standards. We now have many more professional and certified project managers, change managers and project support roles; all overseen by various established governing bodies and key subject groups. However, there seems to be a disconnect in the application of these methods and standards in the real world of projects and the assessment of cultural and political contexts together with areas of knowledge integration (Cicmil et al. 2006; Crawford and Hassner-Nahmias 2010; Soderlund 2011). These findings perhaps highlight that our understanding of IS project failure is incomplete, that although the literature has analyzed failure in detail and listed the key reasons for poor project outcomes; greater analysis or even a different approach to the analysis of failure is required to yield greater insight.

The research method selected for this study is one that is centered on the testing of a specific hypothesis. We pose the following research question: Can patterns of IS failure can be inferred based on a definition of the interrelationships between each of the factors as an output of an empirically derived modeling methodology. This study is positioned as research that can lead to early identification of patterns of failure early in the lifecycle necessitating corrective action, long before projects follow the downward trajectory to failure. This paper attempts to address this hypothesis by analyzing the causal links between IS failure factors and position this enhanced understanding as a key component in attempts to influence IS project outcomes. The research design approach for this study is based on a systematic mathematically derived methodology - Interpretive Structural Modelling (ISM). ISM relies upon empirical data collected from subject matter expert participant input and enables the modelling of interrelationships between IS failure factors. This approach effectively deconstructs the key components of project failure and systematically builds a model that identifies formalized relationships between specific failure factors. This new understanding of these key relationships can help to develop an associative and predictive element to patterns or sequences of failure that can be formally analyzed and modeled.

We develop this work as a valuable new insight into the underlying factors that surround IS project failure and present the research as an effective contribution to the greater understanding of this topic. The findings of this study are presented as of substantive importance to academics involved in this important research area and for practitioners that are closely involved with delivering IS projects within organizations. This work is also of relevance to academics and practitioners involved in initiatives or projects in areas such as: technology, manufacturing, production and process improvement. The implementation of advanced production planning 
and manufacturing concepts is often supported by the development of new IS and the integration with existing systems (Wiers 2002). Additionally, organizations embarking on change or technology improvements or setting up projects to implement new manufacturing facilities or improvements to processes could benefit from the content and findings of this study.

The remaining content of this paper is structured around the following sections: Literature Review, Selection of IS failure variables, Research Methodology, ISM process including the steps required to progress through the methodology, Discussion - including theoretical contribution and Implications for Practice, Conclusions.

\section{Literature Review}

The IS failure literature is broadly based around a number of methodological approaches each contributing to the overall research on this topic.

- Review based studies - literature and taxonomy orientated research.

- Industrial based practitioner research - industry wide studies looking at trends and project performance.

- Case studies - research focusing on a specific instance of project failure or related cases of failure.

- Empirical based studies - research with an empirical element that may for e.g. sample views of project managers or project executives or wider participant groups to gain incite on key issues within IS failure.

- Theoretical and framework driven studies - theoretical based research where perhaps a new framework or model is presented to provide structure or support for the contribution.

Table 1 sets out the key elements of the literature that have been included in this study aligned to the methodological approach. Each of the key studies are listed together with a sample of some of the key extracts from the research.

Table 1: IS Failure Literature Review

The literature has attempted to deconstruct and categorize project failure to better highlight its root causes and various notions (Flowers 1997; Lyytinen and Hirschheim 1987; Pinto and Mantel 1990). Project success has been historically associated with delivering to time, cost and quality, (Sauer 1993), however, it is widely recognized that this a somewhat restricted set of criteria in that the people related factors such as levels of adoption and subsequent benefits realization do not feature (Hughes et al. 2015). Kerzner (2013) highlighted the concept of desired value from the context of the stakeholder perspective, where failure is associated with the projects inability to deliver stated benefits and defined value. Lyytinen and Hirschheim (1987) defined an inclusive structure for failure classification, arguing that previous studies are focused on a largely unarticulated concept of project failure and presented the notions of: correspondence, process, interaction and expectation failure. The triangle of dependencies model as developed by Sauer (1993) emphasized the criticality of stakeholder support for the system and the resulting impact when that support ends. Subsequent studies by Pinto and Mantel (1990) and Flowers (1997) highlight that failure should be judged on the assessment of a number of criteria and common factors. Project failure can sometimes be based on an organizational context, a subjective view from the executive, or an alternative perspective between client and contracting organizations where the notion of profit may take precedence 
over other more stakeholder based factors (Dwivedi et al. 2015; Hughes et al. 2015; Pinto and Mantel 1990).

Researchers have investigated specific cases of project failure (Avison and Wilson 2002; Beynon-Davies 1995, Brown and Jones 1998, Gauld 2007; McGrath 2002; Mitev 1996; Pan et al. 2008) highlighting a number of key factors that have either contributed to or specifically identified as the root causes of IS project failure. These studies have identified a range of failure factors such as: poor project management, problems due to user resistance, poor requirements management and inability to develop a sound business case for the project. Aspects of the IS failure literature have reviewed the key issues of projects failing and have developed new frameworks and models to gain clarity on the root causes and main contributory factors or focused on specific areas of failure (Bronte-Stuart 2009; Ewusi-Mensah 2003; Davis et al. 1992; Goulielmos 2005; Heeks 2002; Keider 1974; Lin and Pan 2011; Nelson 2007; Nixon et al. 2012; Perkins 2006; Poulymenakou and Holmes 1996; Young 2005). The literature has also attempted to develop a comprehensive taxonomy of IS project failure with studies focusing on the empirical and case study based research to gain new perspectives and understanding of the many causes of projects to fail (Al-Ahmad and Al-Fagih 2009; Dwivedi et al 2013; Fenech and Raffaele 2013; Hughes et al. 2015) thereby furthering the debate amongst the academic and practitioner community. Researchers have developed theoretical propositions supported by frameworks or models to identify the key components of the IS failure process from the risk and diagnostic perspective (Bronte-Stuart 2009; Davis et al. 1992; Goulielmos 2005; Heeks 2002), retrospective perspective (Nelson 2007) and social nature of IS (Poulymenakou and Holmes 1996).

Although the literature has developed a comprehensive analysis of IS project failure with numerous papers highlighting common factors, early warning signs, models and processes to avoid failure (Dwivedi et al. 2015; Hughes et al. 2015), few studies have presented an in-depth analysis of the relationships between the various factors. The widely cited study by Flowers (1997) highlighted a set of factors associated with project failure termed - critical failure factors, but although has context in terms of IS failure prediction and prevention the study has not provided an empirical analysis of the links between factors. Based on the analysis of over one thousand projects, Fenech and Raffaele (2013) identified a number of groupings termed failure pillars comprising of: project planning and direction, project management and execution and user management; Hughes et al. (2015) presented a taxonomy of failure factors grouped by people and project management categories to highlight the specific factors associated with each. Both studies whilst attempting to reduce complexity and provide clarity on high-level relationships or associations between factors, have not pursued any deeper analysis of the associations between the failure factors. Lehtinen et al. (2014) examined the relationships between failures within software projects under the grouped categories of: people, methods, tasks and environment using a Root Cause Analysis RCA method. This approach provided a rigorous structure to understanding failure and its causal mechanisms, highlighting the multidimensional nature of failure and interconnection between factors, but focused on these areas from the process improvement and software project perspectives. Further studies have reviewed the causes and relationships between failure factors from a risk perspective (Kappelman 2006; Keil et al. 1998; Schmidt et al. 2001; Wallace at al. 2004) highlighting groupings of related factors and potential early warning signs. However, these studies do not explore these risks from the context of direct causal relationships between failure factors and do not explore the influence that the factors have on each other.

Although the wider literature has focused on ISM as a technique to provide greater understanding of many industry sector applications in: logistics (Ravi and Shanka 2005), knowledge management (Singh et al. 2003), supply chain agility (Agarwal et al. 2007; Agarwal and Shanker 2003, vendor selection (Mandal and Deshmukh 1994), manufacturing (Meade and 
Sarkis 1999; Purohit et al. 2016) and energy conservation (Saxena et al. 1992); few studies have applied the ISM technique to IS. Jitesh et al. (2008) and Thakkar et al. (2008) applied ISM to provide greater understanding of IT enablers for Indian manufacturing organizations, Salimifard et al. (2010) and Singh (2011) modeled critical success factors within banking and SME genres, Samantra et al (2016) analyzed risk factors in the context of software engineering projects, Chander et al. (2013) modeled information security parameters specific to Indian organizations using ISM. These ISM related studies although providing relevance in the context of technical approach, are not directly related to providing greater insight and understanding of IS project failure. From our review of the extant literature on this subject - no previous study on IS failure has utilized ISM as a mechanism to establish potential relationships between IS failure factors.

\section{Selection of IS Failure variables}

An extensive literature review was undertaken to develop the list of IS failure factor variables required for ISM modeling (table 2). The presented factors represent a summarized and synthesized form of the key failure factors from relevant case studies, taxonomy orientated studies and wider research on the key factors surrounding the failure of IS projects.

Table 2: List of IS failure factors

To ensure the integrity of the study and reduce the potential for inadvertent introduction of bias - the factors as listed are not ordered by any priority or categorization based on frequency of occurrence. This ensures the participants are not influenced by any implied ordering or sequencing of the factors.

\subsection{Relationship between organization and external contractor}

Deteriorated relationship between organization and external contracted supplier, leading to project failure. This factor relates to issues arising as a direct result of the poor relationship between an external contracting entity (supplier, vendor) and the organization itself. Instances of these sorts of failures within a project can be catastrophic where the organization and the external IS contractor revert to their respective legal team to resolve the dispute. Many organizations have historically outsourced what they have seen as non-core IS capability to managed service contracting organizations. The net effect of this policy is that there is a strategic reliance on the external contractor and limited options to bring any IS development back in-house when things go wrong.

Organizations that choose not to develop an IS in-house, will invariably use the services of a contracted entity to build and deliver the system. The foundations for an effective working relationship need to be fully laid out within the contract and communication strategy that both parties sign up to. When strategically important interconnections are established it is key for the relationships to be anchored at the organizational level (Wiegel \& Bamford 2015). All too often it is the ability of the contract to be interpreted differently by each party resulting in expensive legal battles as each party seeks redress and attempts to identify blame when projects go awry. Studies highlight that post mortems on large project failures that involve a contractor or consultant relationship often state that either the consultant did not have the skills to deliver the project or the consultant underestimated the complexity and scope of the project (Nawi et al. 2011; Verner and Abdullah 2012; Yeo 2002).

The project case histories as outlined in Brown and Jones (1998) and Warne and Hart (1997), highlight instances where the organizations concerned had either failed to formally prepare for 
change, were inexperienced in working with external organizations or had underestimated the impacts and complexities of large outsourced projects. These projects exhibited problems where difficulties were experienced in managing the contractor relationship with stakeholders not understanding the methods and approach of the contractor. These factors coupled with the intimidation felt by some stakeholders in their relationship with external organizations can further contribute to the failure of projects (Brown and Jones 1998; Warne and Hart 1997).

\subsection{Executive support and project sponsorship}

Lack of a nominated sponsor for the project, poor support from the sponsor and executive board. This factor relates to the project impacted by the performance and commitment of the executive and/or project sponsor. The sponsor would normally own the business case for the project, therefore in instances where the project suffers from ineffective or poor project sponsorship can be fatal. Identifying and gaining the commitment of the best senior representative to perform this role is vital to the success of a project.

Support for a project from the organizations top management is fundamental for successful outcomes with studies highlighting that the effectiveness of the sponsor is one of the strongest predictors of success or failure (Nixon 2012; Prosci 2012; Young 2005). Studies surveying the experiences of practitioners have emphasized instances where project have suffered due to executives lacking engagement with the project, ineffective sponsorship and overall lack of commitment from senior management (Emam and Koru 2008; Keil et al 1998; Lemon et al. 2002; Schmidt et al. 2001; Standing et al. 2006). The abandoned IS project at Gardenco - a New Zealand manufacturing company, highlighted the significant problems faced by the project due to the absence of an executive sponsor and lack of support from the board (Busssen and Myers 1997). The collapse of One-Tel in 2001 highlighted the impact of a complete lack of formal management structure and its negative effects on the project (Avison and Wilson 2002). Ineffective executive leadership and poor project sponsorship were key reasons for failure in the ERP implementation as outlined by Pan et al. (2008) and the Health Information Systems (HIS) project as studied by Gauld (2007).

\subsection{Business Case, estimating and financial management}

Weak or poorly defined business case where project benefits are not clearly defined or properly estimated and poor financial management of the project. A project that is up and running with a poorly specified or unclear business case is unlikely to succeed as the core budget, organization and project benefits are unlikely to be sufficient to drive success.

The literature has identified a number of projects where failure can be associated with an unclear business case. These studies identify projects that have an inadequate business case and poorly defined objectives highlighting the impact of not formalizing the key project benefits early in the project (Sauer et al. 1997; Standing et al. 2006; Ward and Elvin 1999). Without a clear business and financial justification for the project it is unclear how the project can be specified, managed or delivered successfully. Studies have emphasized how a culture of poor cost control and budget deviations are key factors in the failure of projects (Conboy 2010).

\subsection{Staff Performance}

Reduced performance of staff - often due to lengthened timescales and excessive hours. This factor highlights the key issues on projects where timescales and schedules are directly impacted by the performance and commitment of staff. 
Studies have identified that project failure has been influenced by the performance, commitment, turnover and motivation of staff with these issues becoming more apparent on long lead-time projects with dispersed teams across multiple geographic boundaries (Bussen and Myers 1997; Michie and West 2004; Newman and Sabherwal 1996; Rob 2003). The culture within technology-based organizations has for many years been one of staff working long hours as they struggle to develop and deliver a system to short timescales and unrealistic budgets leading to an eventual reduction in performance, increased cynicism and stress levels due to temporal dissonance (Conway and Limayem 2011; Linberg 1999. Verner et al 2008).

\subsection{Post mortem process}

Organizations failing to learn lessons from past mistakes and repeating the causes of failure. This is a factor directly related to organizations not having the commitment, will or processes in place to understand the root cause of existing and past failures and address these issues for future projects. Learning the lessons of past IS failures has been something that organizations, governments and the IS industry itself have been extremely slow to realize. Studies have identified industry trends where high numbers of projects have failed for similar reasons to previous failed projects within the same organization and that $81 \%$ of organizations do not undertake a post-mortem on their projects (Ewusi-Mensah and Przasnyski 1995). Low levels of project post mortem and in some cases only conducting post delivery reviews exclusively on successful projects; demonstrates a culture of hiding mistakes and inadvertently creating a cycle of failure (Verner et al. 2008; Kerzner 2013).

\subsection{Size and complexity of project}

Failure as a direct result of the project being too large and complex. This factor directly relates to projects described as large with associated long lead-times and high levels of complexity. These types of project can be extremely difficult to manage and incur significant levels of risk in terms of budgets, timescales stakeholder satisfaction and therefore, benefit realization.

Large and complex IS projects have a dismal record of successful delivery with industry wide studies highlighting that this genre of project is more likely to fail outright than less complex, smaller projects. Aspects of the literature that have reviewed large IS project failures have identified some of the classic large project problems: excessive complexity, poor management of key users, stakeholders unable to understand the complex system, poor governance, high levels of complexity and integration (Gauld 2007; Jones 2004; Jones 2006; Mitev 1996; Nawi et al. 2011; Verner and Abdullah 2012). Large-scale strategic ERP failures such as those outlined in Barker and Frolick (2003) Pan et al. (2008) and Wiers (2002) indicate the significant problems delivering and integrating these types of projects and perhaps indicate that due to their complexity, failure at some level is inevitable (Scott and Vessey 2000). Studies have questioned whether project scale and complexity by themselves are key factors or that additional scale derived risk factors materialize necessitating that perhaps the project should be managed differently (Jones 2006). Studies have theorized as to whether large projects should ever be initiated, as the likelihood of a successful outcome is so remote (Standish Group 2013). Project sponsors and senior management can often exhibit blind faith that success will be achieved as large amounts of money, resource and corporate reputations are at stake on large and complex projects (Kerzner 2013). 


\subsection{Project management and risk management}

Project management failings and poor risk management. This factor directly relates to the performance of the project manager in the management of risk and the management of the project itself. The project management role is pivotal for success especially as most projects operate under a regime of delegated authority within the constraints of each stage or phase.

Project failings due to poor project management is a frequently cited failure factor in the literature (Emam and Koru 2008; Keil et al. 1998; Verner et al. 2008). Studies highlight project management immaturity, lack of control, management style and poor implementation of methodology as key factors (Avison and Wilson 2002; Philip et al. 2009; Scott and Vessey 2000; Standing et al. 2006). The impact of not managing project risk effectively has featured in many empirical studies surveying the experiences of practitioners and organizations (Jones 2004; Tukel and Rom 1998; Verner et al. 2008; Wallace et al. 2004). Issues such as: not assessing risks effectively, poor risk assessment and control, inaccurate estimation of risk all feature as contributory factors in the failure of projects (Jones 2004; Keil et al. 1998; Pan et al. 2008).

\subsection{Requirements and scope management}

Poor definition and management of project requirements; poor management of project scope. This factor relates to failings as a direct result of inadequate requirements definition or poorly managed scope creep during the project lifecycle.

Project failure due to poor definition and not effectively managing project requirements, has been frequently cited in the literature (Brown and Jones 1998; Bussen and Myers 1997; Emam and Koru 2008; Keil et al 1998; Nawi et al. 2011; Pan et al. 2008; Schmidt et al. 2001). Managing the requirements process for large, long lead-time projects is especially difficult as the realities of defining an up-front detailed set of requirements for such complex systems become apparent all too clearly later in the lifecycle (Bussen and Myers 1997; Nawi et al. 2011; Pan et al. 2008).

\subsection{Stakeholder Communication}

Project failure due to communication between stakeholders and inadequate project communications. This factor relates to failings in the project as a direct result of poor communications internal to the project or amongst the wider stakeholder base. Issues arise on projects where large numbers of stakeholders are involved and project teams do not adequately analyze the appropriate method, frequency or form of communication.

Inadequate communication with users and the wider stakeholder base can be a key contributory factor in the failure of projects. Poor communication between client and vendor, negative outcomes as a direct result of poor communication between staff and stakeholders, poor communication during ERP implementation, barriers to communication, poor communications between exec, middle management and front line staff are all contributory factors to project failure (Barker and Frolick 2003; Gauld 2007; Monteiro de Carvalho 2014; Philip et al. 2009; Rob 2003).

\subsection{Employee Resistance}

Poor management of stakeholder resistance and key factors surrounding the inability of projects to manage this effectively. This factor is associated with the users not willing to accept 
the changes to the system or processes or other project initiatives. Unresolved user resistance issues can be catastrophic for projects and unless dealt with can impede the realization of project benefits.

High levels of user resistance are referenced in a number of studies as root causes of project failure. (Barker and Frolick 2003; Fitzgerald and Russo 2005; Hirschheim and Newman 1988; Keil et al. 1998; McGrath 2002; Mitev 1996; Pan et al. 2008; Scott and Vessey 2000). Many projects have suffered the consequences of not investing enough time and resources in the people side of projects highlighting: failure to involve users within the early stage of the project, inadequate communication of changed processes, poor management of user resistance within the organization and resistance stemming from the projects over emphasis of the technical aspects of delivery (Beynon-Davies 1995; Bown and Jones 1998; Fitzgerald and Russo 2005; Gauld 2007; McGrath 2002).

\subsection{Change Management}

Inadequate management of organization change and the individual change aspects of the project. This factor relates to failings on the project directly resulting from inadequate emphasis and focus on the organizational change elements within the project. Project managers and executives have often ignored the impact on users resulting from the change to their working practices and daily interaction with new systems focusing too much on the technical aspects of delivery.

Managing the process of successful change within an organization is extremely difficult, requiring the adoption of a core competency and methodological approach that requires the involvement of employees throughout the organization to realize successful sustained outcomes (Buchanan et al. 2005; Burnes 2005; Pettigrew and Whipp 1993). However, numerous project failures have highlighted that the key aspects of individual and organizational change have not been managed effectively (Barker and Frolick 2003; Beynon-Davies 1995; McGrath 2002; Mitev 1996).

\subsection{Planning}

Unrealistic delivery dates and poor planning of deliverables. This factor relates to inadequate definition of timescales and unrealistic deadlines for the project deliverables. Unachievable project plans can be a big demotivator for staff and a sure sign that the project is not under control. Gaining commitment to a project plan is a key early stage activity.

IS failure studies have identified that poor project planning issues are key contributory factors in the failure of projects (Emam and Koru 2008; Jones 2004; Keil et al. 1998; Standing et al. 2006; Verner et al. 2008; Yeo 2002). Large projects, especially those in the public and health sectors that are not planned effectively, have a significant risk of failure (Gauld 2007; Nawi et al. 2011; Pan et al. 2008; Philip et al. 2009). Studies have identified that a significant proportion of problems that led to failure were direct result of poor planning (Nawi et al. 2011; Yeo 2002).

\subsection{Evaluation or pilot stage}

Failure due to not conducting an evaluation or pilot stage. Unwillingness to conduct an evaluation or omission of product or solution feasibility prior to commencement of the project. Projects with an uncertain business case or have unanswered questions on scope or solution can suffer from failure further along the project lifecycle where these aspects should have been dealt with at feasibility. 
Organizations that have forged ahead with projects without undertaking proper product evaluation or feasibility often end up carrying risk throughout the project. The ERP related studies of Barker and Frolick (2003) and Pan et al. (2008) highlight the issues where specific projects either did not undertake a product evaluation process or the evaluation processes followed was flawed leading to high levels of user resistance and a plethora of contributory failure factors. Many organizations have been shown to dive in at the deep end only to regret not taking time to evaluate potential solutions early in the lifecycle.

\subsection{Staff turnover}

Departure of key staff having a significant impact on the project. This factor relates to the problems caused on projects as a direct result of key staff leaving the project. Typically, key technical or managerial skills are difficult to replace within organizations resulting in a direct impact on timescales delivery of timely project benefits.

Studies have identified that project failure has been influenced by the turnover of staff within organizations (Bussen and Myers 1997; Conway and Limayem 2011; Linberg 1999; Michie and West 2004; Newman and Sabherwal 1996; Rob 2003; Verner et al 2008). Modern IS projects tend to involve a highly skilled mix of technical, managerial and people orientated resource. When this resource is not managed effectively and staff leave, this can have a significant impact on outcomes.

\subsection{Training}

Lack of or inadequate training seen as a contributory factor to the project failure. The lack of provision for training in the project budget or schedule can have a direct impact on successful delivery. This factor also includes instances of inadequate or poor training on new systems processes or working practices.

Lack training support and instances of poor training are cited as a contributory factor in the failure of IS projects (Barker and Frolick 2003; Jiang et al. 1998; Winklhofer 2001). Training is a key aspect of project delivery in that if this activity is not performed adequately, then adoption issues may arise and delays could result in the realization of project benefits.

\section{Research Methodology - ISM Process}

The research design approach for this study is based on a systematic mathematically derived methodology - ISM. ISM enables the visual representation of a complex problem via a systematic process based on the structural modeling of interconnected matrices (Warfield 1974). This approach imposes classification and direction on the relationships between elements within a complex system (Sage 1977).

The ISM method was first proposed by Warfield (1974) as a procedure for demonstrating matrix interconnection via binary relation characterized by logic equation. ISM is a two-phase process drawing on the principles of discrete and finite mathematics. The ISM process has been shown to be a useful technique able to transform poorly defined mental models of systems into clear structured well-defined models (Sage 1977). Studies have used the ISM method to identify interrelations between a set of variables or elements and to highlight potential influences and dependencies between these variables portrayed in a directed graph (digraph) model (Agarwal et al. 2007). ISM was selected as the method of choice due to its strengths in the identification of interrelationships between individual factors and structured mathematically derived process. ISM has been shown to be an extremely useful method when dealing with a set of participants within a group of subject experts where a consensus is required on the 
relationships between a set of variables (Dwivedi et al., 2016; Ravi and Shanka 2005). ISM is traditionally presented as a group learning process but can be used individually as was the case in this study. Conceptually, the participants reach agreement after assessing the various viewpoints of the group and a consensual view is formed (Agarwal 2007; Janes 1988). This interpretive approach is a considerable strength of the method where by, an expert view on the interrelationships is a defined output of the process. In practice the process of reaching agreement between the participants requires debate and iteration on the review of the perceived relationships between the set of variables.

The ISM process as applied to this study is set out in figure 1. The process is step-by-step structured method that starts with the definition of a set of variables that are an output of an initial investigation exercise or literature review. Following an assessment of the elements by an expert participant group, the contextual relations between the variables are represented in a Structural Self Interaction Matrix (SSIM). From this step, based on a set of rules the Initial Reachability Matrix (IRM) is prepared from the SSIM. The next step in the process is to incorporate transitivity to the matrix after which the Final Reachability Matrix (FRM) is obtained. The FRM is then progressed to level partitions where for each of the matrix elements the reachability, antecedent and resulting intersection sets are derived. This process of iterating through the partition levels continues until the bottom level in the ISM hierarchy is reached. The next step entails the development of the canonical matrix where the elements are clustered based on the levels defined in the previous step where the driving and dependence power are identified for each element. After removing all transitive links a digraph is developed that diagrammatically represents the driving and dependence power influence of the individual elements in the conical form of the matrix. A final ISM model is then developed that represents the digraph content where the nodes are replaced by the element statements and their relationships between the levels are identified.

Nine participants were selected for the review and analysis of the IS failure factor variables. The chosen experts are practitioners working in the field of IS from a wide range of sectors: healthcare, finance, consultancy, government agency and defense. Each are in the process of undertaking: change management, business analysis and project manager roles within their organizations. The participants were specifically selected to provide their expert opinion and offer a proportional balanced view on the relationships between the selected IS failure variables for the ISM process.

Figure 1: ISM Process

\section{ISM Process and Results}

This section outlines the required steps and process for progressing through the ISM method. The results at each stage are fully detailed identifying the specific ISM characteristics and outputs of the method for each step.

\subsection{Structural Self Interaction Matrix (SSIM)}

The participant group were requested to analyze the matrix of variables and identify interrelationships between them based upon the ISM rules and their expert opinion. The selected variables are: 1) Relationship between organization and external contractor, 2) Executive support and project sponsorship, 3) Project business case 4) Staff performance, 5) Post mortem process, 6) Size and complexity of project, 7) Project management and risk management, 8) Requirements and scope management, 9) Stakeholder communication, 10) Employee resistance, 11) Change management, 12) Planning, 13) Evaluation or pilot stage, 14) Staff turnover, 15) Training. 
The ISM based relationships between the selected variables are described in the context of how one variables influences another variable and how a particular variable may be influenced itself by a separate variable in the matrix. The SSIM matrix is set out in figure 2 where the interaction between the variables is described in terms of $i$ (rows) and $j$ (columns) and their association. This expert assessed identification of specific relationships between variables is denoted via a simple notation using the following symbols: V, A, X, O.

$\mathrm{V}$ : variable $\mathrm{i}$ will help to achieve or have influence on variable $\mathrm{j}$;

A: variable $\mathrm{j}$ will be achieved or influenced by variable $i$;

$\mathrm{X}$ : variable $\mathrm{i}$ and variable $\mathrm{j}$ will help achieve or influence each other;

$\mathrm{O}$ : variables $\mathrm{i}$ and $\mathrm{j}$ are not related.

Figure 2: Structural Self-Interaction Matrix

By way of an example to explain the population of the matrix in figure 2: The expert participants identified that Executive support and project sponsorship (2) has an influence over employee resistance (10). Therefore, a $\mathrm{V}$ is inserted in the matrix at the $\mathrm{i}, \mathrm{j}$ cell reference: $2: 10$. The variable planning (12) is seen by the participant group as having no influence over training (15) or visa versa, they are therefore, unrelated, this is defined in the matric by the symbol $\mathrm{O}$ at the $\mathrm{i}, \mathrm{j}$ cell reference: $12: 15$. The matrix is populated using this notation until all the cells are completed. The shaded section in figure 2 demarks the area of duplication references as these relationships are already covered elsewhere in the matrix.

\subsection{Initial Reachability Matrix (IRM) and Final Reachability Matrix (FRM)}

The next step in the ISM process is the development of the initial and final reachability matrices (ISM and FRM). The notation in the SSIM is converted to a binary format where the following rules govern the transformation process:

i) if the (i,j) cell entry in the SSIM is V, then the equivalent $(i, j)$ entry in the IRM becomes: 1 and the $(\mathrm{j}, \mathrm{i})$ cell entry becomes: 0 ;

ii) if the $(i, j)$ cell entry in the SSIM is A, then the equivalent $(i, j)$ entry in the IRM becomes: 0 and the $(j, i)$ cell entry becomes 1 ;

iii) if the $(i, j)$ cell entry in the SSIM is $X$, then the equivalent $(i, j)$ entry in the IRM becomes: 1 and the $(\mathrm{j}, \mathrm{i})$ cell entry also becomes 1 ;

iv) if the $(i, j)$ cell entry in the SSIM is $O$, then the equivalent $(i, j)$ entry in the IRM becomes: 0 and the $(\mathrm{j}, \mathrm{i})$ cell entry also becomes 0 ;

Figure 3 highlights the completed matrix when all the cell references have been converted to binary format as per the rules outlined above.

Figure 3: Initial Reachability Matrix (IRM)

The FRM as shown in figure 4 extends the IRM to include transitivity. Transitivity is highlighted in the FRM by the notation $1^{*}$. The high level concept of transitivity can be described in the context of:

If $\mathrm{A}$ is connected to $\mathrm{B}(\mathrm{A} \rightarrow \mathrm{B})$ and $\mathrm{B}$ is connected to $\mathrm{C}(\mathrm{B} \rightarrow \mathrm{C})$ then we can say there exists a transitive relationship between $A$ and $C(A \rightarrow C)$. The process to develop the FRM from the IRM to include transitivity can be written as: 
$\forall \mathrm{i} \forall \mathrm{j} \forall \mathrm{k}$, if $\exists \mathrm{k}$ such that $\mathrm{k} \neq \mathrm{i}$ and $\mathrm{k} \neq \mathrm{j}$

$$
(\mathrm{M}[\mathrm{i}, \mathrm{k}]=1) \wedge(\mathrm{M}[\mathrm{k}, \mathrm{j}]=1) \wedge(\mathrm{M}[\mathrm{i}, \mathrm{j}]=0) \text { then } \mathrm{M}[\mathrm{i}, \mathrm{j}]=1^{*}
$$

Where $\mathrm{M}$ is the IRM, $\mathrm{i}, \mathrm{j}$ represent the rows and colums respectively and $\mathrm{k}$ represents the $(\mathrm{i}, \mathrm{j})$ cell reference in the transitivity process. The symbol $\forall$ represents for all instances of: i,j,k. Then if $\exists$ denotes a match between column instance ' 1 ' and row instance ' 1 ' at location $\mathrm{k}$. The interjection symbol: $\wedge$ is used to verify: $(M[i, k]=1 \wedge(\mathrm{M}[\mathrm{k}, \mathrm{j}]=1)$. If all three conditions are true i.e. If $(M[i, j]=0)$ and $(M[i, k]=1)$ and $(M[k, j]=1)$, then we set $M[i, j]=1 *$ to signify transitivity at this cell reference in matrix $\mathrm{M} . \mathrm{k} \neq \mathrm{i}$ and $\mathrm{k} \neq \mathrm{j}$ represents the $\mathrm{n}: \mathrm{n}$ instances that are ignored for this method. The approach used to identify transititivity outlined in equation (1) to populate the FRM is as follows:

Step 1: Start from row 1 of the IRM and work down to row n. Identify all instances of ' 1 ' in row 1(j) and note these to aid the next step. Ignore n:n references e.g. 1:1

Step 2: For each instance of a 0 across the full row (j) look down on the specific column (i) and reference against each previously noted instance of '1' from first row but now against the column.

Step 3: If a match is found in step 2 then convert any instances of 0 in above scenario to $1^{*}$ and continue to the next instance of 0 across the row (j). Continue with this method until the complete matrix is checked for transitivity.

Figure 4: Final Reachability Matrix (FRM)

\subsection{Partitioning of the FRM}

The completed FRM from the previous step must now be assessed based on the reachability and antecedent sets for each of the variables in the matrix (Warfield 1974). The reachability set $\mathrm{R}(\mathrm{Pi})$ and antecedent set $\mathrm{A}(\mathrm{Pi})$ need to be populated in the next step. The reachability set $\mathrm{R}(\mathrm{Pi})$ consists of the element itself together with other elements, which it may help to achieve. This is set out in figure 4 as the instances of 1 and $1^{*}$ for each of the variables (i) across all the rows (j). The antecedent set A(Pi) consists of the element itself and other elements, which may help in achieving it. This is outlined in figure 5 by listing the instances of 1 and $1 *$ for the column (j) that corresponds with each variable (i). The intersection of these two sets $\mathrm{R}(\mathrm{Pi} \cap \mathrm{A}(\mathrm{Pi}))$ is the final element of the top-level partition matrix where the common elements between $\mathrm{R}(\mathrm{Pi})$ and $\mathrm{A}(\mathrm{Pi})$ are listed in the final column.

Figure 5: Level Partition - Iteration I

In this first level of the partition matrix the top level of the hierarchy is identified where there is a match between the reachability $\mathrm{R}(\mathrm{Pi})$ and intersection sets $\mathrm{R}(\mathrm{Pi} \cap \mathrm{A}(\mathrm{Pi}))$. Where a match exists; i.e. $\mathrm{R}(\mathrm{Pi})=\mathrm{R}(\mathrm{Pi} \cap \mathrm{A}(\mathrm{Pi}))$ then $\mathrm{a} \mathrm{I}$ is inserted against the appropriate variable. The matching elements identified in figure 4: (1) Relationship between organization and external contractor, (4) Staff Performance, (10) Employee Resistance, (14) Staff turnover are the top level variables in the hierarchy and as such do not help to achieve any other variable at a higher level in the ISM model. This process is continued for the next level partition but for the next iteration the elements outlined in level I are removed from the matrix. This step is outlined in figure 6.

Figure 6: Level Partition - Iteration II 
Iteration II as outlined in figure 6, highlights the matches between $\mathrm{R}(\mathrm{Pi})$ and $\mathrm{R}(\mathrm{Pi} \cap \mathrm{A}(\mathrm{Pi})$ ) for the next level with the previous level matching variables removed. The matching elements at this level are: (3) Project business case, (6) Size and complexity of project, (7) Project management and risk management, (8) Requirements and scope management, (9) Stakeholder communication, (11) Change management, (12) Planning, (13) Evaluation or pilot stage, (15) Training. These elements will be positioned at the $2^{\text {nd }}$ level of the ISM model.

Figure 7: Level Partition - Iteration III

Figure 7 highlights the variables within iteration III of the level partition process. Matches are found for variables: (2) Executive support and project sponsorship and (13) Evaluation or pilot stage. These elements will form the $3^{\text {rd }}$ level in the ISM model.

Figure 8: Level Partition - Iteration IV

The final iteration of the level partition process is shown in figure 8. Variable (5) Post mortem process, is the remaining variable at this level and will be positioned at the lowest level in the ISM model.

\subsection{Development of the Canonical Form Matrix}

The development of the canonical form of the matrix is the next step in the ISM process and is shown in figure 9. This matrix is a reorganized version of the FRM where the variables are clustered to align with the groupings from the level partition stage. We can now observe from the Canonical form that the ordering of the variables aligns with the instances of $R(P i)=R(P i$ $\cap \mathrm{A}(\mathrm{Pi})$ from the previous step. We can see from the ordering of the variables that the top level of the ISM model will be to the left of the Canonical matrix and the variables to the right will appear at the bottom of the model.

Figure 9: Canonical form of FRM

\subsection{Driving and Dependence Power - (MICMAC) Analysis}

The purpose of the MICMAC - Matrice d'Impacts Croises - Multiplication Applique a un Classement (Cross impact matrix-multiplication applied to classification)) element of the ISM process is to analyze the drive power and dependence power of the variables and multiplication properties of matrices (Sharma et al. 1995; Mandal and Deskmukh 1994). This element of the ISM process is used to identify the key enablers that drive the system in terms of the IS failure factor influence. The driving and dependence powers are populated by summing the " 1 " entries for each of the variables along the rows and columns for each of the variables in the matrix as shown in figure 10 .

Figure 10: Driving and dependence power applied to the Canonical form matrix

The influence of the power and dependency aspects of the relationships between the variables is shown via the MICMAC diagram in figure 2 and classifies the four quadrants as follows:

- Autonomous - identifies variables that have weak driving power and weak dependence and therefore, low impact. This means they are relatively disconnected from the system having few links to other variables. 
- Linkage - identifies variables that have strong dependency power and strong driving power. As such the variables within this quadrant are classed as unstable as any action on these variables will have a corresponding effect on other variables and feedback on themselves.

- Dependent - identifies variables that have strong dependence power but weak driving power.

- Independent - identifies variables that have weak dependency power but strong driving power and are often termed - key factors.

Figure 11: MICMAC Diagram

The location of the IS failure factor variables with the MICMAC diagram in figure 11 is mainly located within the Linkage quadrant. This clustering of the variables in this region highlights the unstable characteristics of this set of variables. The majority of the variables in this quadrant are of strong dependency power and strong driving power. This means that any action on these variables will have a corresponding effect on other variables and feedback on themselves. The key characteristic of these linkage variables is that by their nature and large amount of interconnections, any failings in one area can result in corresponding failures in other connected areas.

Two variables: 5) Post mortem process, 13) Evaluation or pilot stage are located within the Independent quadrant. These variables have weak dependency power but strong driving power. As such they have high levels of influence on connected variables at higher levels in the digraph. One variable is located within the Dependent quadrant - 4) Staff performance. Dependent variables have strong dependence power but weak driving power. This means that these factors are normally at the top layer of the digraph and are directly influenced by other related factors. There are no variables located within the Autonomous area of the cluster diagram.

The clustering of the remaining variables is centered within the Linkage quadrant. But on closer inspection we can see a sub-section of clustering of variables within this quadrant; 10) Employee resistance, 14) Staff turnover are located to the right of the quadrant with a maximum dependence but lower driving power; 2) Executive support and project sponsorship, 6) Size and complexity of project, 15) Training, are located to the top left of the Linkage quadrant. These variables have maximum driving power but lower levels of dependence power in relation to the other variables within the quadrant. The remaining variables within the Linkage quadrant are: 3) Project business case, 11) Change management, 7) Project management and risk management, 8) Requirements and scope management, 12) Planning, 9) Stakeholder communication, 1) Relationship between organization and external contractor. All exhibit strong dependence and strong driving power relative to the other variables within the quadrant.

\subsection{ISM Model/Digraph}

The final stage of the ISM process is the development of the ISM model or digraph as shown in figure 12. The digraph represents the visual depiction of the variables and their associations with each other as identified within the individual stages of ISM process. The digraph is structured around the ordering of the variables within the canonical matrix and developed in adherence to the following axioms: i) no two distinct lines are parallel and ii) there are no loops (Sage 1977). The top level of the ISM diagram identifies the four variables that were identified in the level I partition processing, namely: 1) Relationship between organization and external contractor, 4) Staff Performance, 10) Employee Resistance, 14) Staff turnover. All have maximum levels of dependence power but varying levels of driving power. This means that this 
layer of the digraph is heavily dependent or influenced by the connections in the next lower level of the digraph.

Figure 12: ISM Model/Digraph

The next layer depicts: 3) Project business case, 6) Size and complexity of project, 7) Project management, 8) Requirements and scope management, 9) Stakeholder communication, 11) Change Management, 12) Planning, 15) Training. This layer of the digraph is heavily populated in that eight of the variables are located at this level. These variables have in the main strong links to each other and also strong links to the layer above. The variables at this layer of the digraph exhibit strong levels of driving power and dependence power. This means that are act as strong influencers of other connected variables and are heavily influenced by connected factors. The third layer contains: 2) Executive support and project sponsorship, process, 13) Evaluation or pilot stage. The remaining bottom layer and the lowest level of the ISM model is: 5) Post mortem process. These variables exhibit strong levels of driving power and relatively low levels of dependency when compared to other variables in the model. This means that these variables are strong influencers of interconnected variables.

\section{Discussion}

The key question posed earlier in the study, namely: Are there patterns of failure that can be highlighted early in the lifecycle necessitating corrective action, long before projects follow the downward trajectory to failure? Is addressed in this section. The findings clearly highlight specific links between failure factors and the strength of the relationships in the context of their dependency and driving power. These findings suggest that based on the identification of causal links between factors, potential exists for the early identification of key factors associated with failure before the factor(s) critically impact the project. The set of IS failure factors (table 2) have been processed through the ISM method and the identified interrelationships have been developed via the MICMAC analysis and digraph (figures 11 and 12). The following sections develop a more detailed analysis of findings, highlighting the theoretical contributions and alignment with existing research together with the implications for practice based on the research findings.

\subsection{Discussion of Findings}

A large proportion of the IS failure factors have high levels of dependency on each other and also act as strong drivers in their relationship to other factors in the model. Most of the variables are located within the Linkage quadrant of the MICMAC analysis; emphasizing the strong dependency and strong driving power nature of these factors. This indicates high levels of instability, as any action on these variables has a corresponding effect on other variables and feedback on themselves. Therefore, in an instance where for e.g. a project suffers from problems due to: 7) Project management and risk management, 8) Requirements and scope management or 12) Planning; we can state that due to their Linkage behavior, other variables within this quadrant could potentially become issues on the project. Alternatively, these particular variables could be impacted if the project suffered from problems due to other factors that reside in this quadrant. These findings align with those from Lehtinen et al. (2014) who highlighted the multi-dimensional nature of failure and interconnections between the factors.

The variable 2) Executive support and project sponsorship is a key factor in the context of its influence on other variables in the model. The MICMAC analysis identifies the maximum level of driving power for this factor. This is supported in the digraph where it is shown as a key 
driver for all the variables at the next highest layer. Additionally, its position and interconnections in the digraph illustrates its high influence on the other variables in the model. To extend this further, in instances where a project suffers from inadequate executive support and project sponsorship we can conclude from the ISM analysis that a number of other potential linked factors could materialize on the project. Previous studies have identified poor project sponsorship as a key cause of IS project failure (Nixon 2012; Prosci 2012; Young 2005). Ineffective executive leadership and poor project sponsorship have been identified as key contributors in the ERP project as outlined by Pan et al. (2008) and the Health Information Systems (HIS) project presented by Gauld (2007). Although the literature has emphasized the key influence of this factor in previous studies, the significant finding in this study is the degree of the potential influence this factor has on a large number of other interconnected factors. Interestingly, previous ISM related studies have analyzed the influence and relationship of lack of top management commitment and support (Luthra et al. 2011; Faisal 2010) and highlighting the strong levels of driving power for this factor. Studies have consistently emphasized the importance of top management support and commitment (Cullen and Taylor 2009; Prosci 2012; Rockart 1982) and its influence on success and failure within organizations, the findings in this study support this view.

The variable 6) Size and complexity of project, is identified as having a significant driving relationship to 3) Business Case and 7) Project management and risk management within its own level in the digraph and also to all the variables at the top level of the digraph; namely: 1) Relationship between organization and external contractor, 4) Staff Performance, 10) Employee Resistance, 14) Staff turnover. These interconnections reflect the high degree of impact on the project when failure stems from this factor and supports previous studies where a projects size and complexity is a key failure factor (Gauld 2007; Jones 2004; Jones 2006; Mitev 1996; Nawi et al. 2011; Verner and Abdullah 2012). The digraph also highlights that 6) Size and complexity of project is influenced by the factor 13) Evaluation or pilot stage. This specific finding highlights the potential influence on this factor from poorly performed evaluation or instances where no evaluation or pilot was performed on the project (Barker and Frolick 2003; Pan et al. 2008). This specific finding suggests that the outcome of projects categorized as large and complex can be influenced by the conducting of an evaluation stage.

Specific factors in the model exhibit significant influence on a large number of other factors in the model. The variables: 6) Size and complexity of project, 7) Project management, 9) Stakeholder communication, 11) Change Management and 12) Planning are identified in the digraph as having high levels of interdependency on each other and also strong driving power in their relationship with the factors in the next layer in the digraph. This indicates the high levels of correlation and influence between these variables and their respective influence on failure. Project failure is likely to be heavily influenced if any of these factors are highlighted as a key factor within a project.

The factor 11) Change management is a key driver for many of the people related factors in the model, namely: 1) Relationship between organization and external contractor, 4) Staff Performance, 10) Employee Resistance, 14) Staff turnover. As such projects that suffer from poor change management (Barker and Frolick 2003; Beynon-Davies 1995; McGrath 2002; Mitev 1996) are shown to be highly likely to suffer from other associated people related failings.

Resistance to change from the employees in an organization is heavily dependent a large number of related factors. The factor -10) Employee Resistance is shown in the MICMAC analysis to exhibit maximum levels of dependency. This means that this factor is strongly influenced by other related factors in the model and has been identified in previous studies as being a root cause of project failure (Barker and Frolick 2003; Fitzgerald and Russo 2005; Hirschheim and Newman 1988; Keil et al. 1998; McGrath 2002; Mitev 1996; Pan et al. 2008; 
Scott and Vessey 2000). Previous ISM related studies have included employee resistance as a factor (Luthra et al. 2011; Talib et al. 2011) confirming the strong levels of dependency and resulting influence on this factor from other related variables.

\subsection{Theoretical Contribution}

Although previous studies have analyzed the potential links between IS failure factors in particular reviewing instances of failure from the risk perspective (Kappelman 2006; Keil et al. 1998; Lehtinen et al. 2014; Schmidt et al. 2001; Wallace at al. 2004) highlighting groupings of related factors, and potential early warning signs of failure; these studies do not explore these risks from the context of direct causal relationships between failure factors. Furthermore, previous IS oriented studies have not utilized ISM as the selected method of choice. We believe this study is the first (to our knowledge) to incorporate ISM as the methodology for analyzing the factors associated with IS project failure and to develop associative links between the factors as shown in the digraph and associated text in this study. By leveraging ISM in this way, we are able to provide fresh insight to the interrelationships between failure factors that have not been exposed in previous studies. We position this as a key contribution to the body of knowledge in the field of Information Systems.

A further key contribution within this study is the identification of links between failure factors and how these links are represented in the context of their dependency and driving power in relation to other factors. This can be seen via the digraph shown in figure 3, the model positions the top-level variables as: 1) Relationship between organization and external contractor, 4) Staff Performance, 10) Employee Resistance, 14) Staff turnover. As these variables are all represented at the top of the model, they are judged to be the variables that have the highest significance in terms of dependency on the other factors. The net effect of this is that these variables are heavily influenced by all connected factors represented. The bottom level variables in the digraph, namely: 2) Executive support and project sponsorship, 13) Evaluation or pilot stage, 5) Post mortem process have the highest levels of driving power, therefore, demonstrate significant influence on other factors in the model. These aspects of the study underpin the significance of this contribution, in that by identifying the key dependence and driving factors; we are able to better understand the impact on projects where these areas are subject to failure. Armed with this knowledge, senior management are better able to understand the early symptoms or warning signs of failure (Kappelman 2006) and implications of how the clustering of factors (Wallace 2004) can potentially exacerbate failure. Studies have highlighted the influences on critical success factors and performance outcomes (Dwivedi et al. 2015, Nudurupati et al. 2015). By increasing our understanding of failure and its dependencies, we are better able to align with successful outcomes and improve benefits to the organization.

The IS failure literature has in the main omitted to establish a greater understanding of the causal links between factors (Hughes et al. 2015). The formal development of these links and the subsequent potential predictive causal associations between factors as identified in this research, is positioned as a significant theoretical contribution.

\subsection{Implications for Practice}

Academics and practitioners alike have attempted to develop theoretical propositions and greater emphasis on standards and methodologies to help to avoid IS project failure. However, few studies have demonstrated a clear path to enhancing a greater understanding of the interrelationships between the key failure factors. The findings of this research are positioned as being of importance to academic study but also to practitioners searching for a mechanism and structure to the many and varied interrelationships between the root causes of IS project 
failure. The following are a list of the findings and interpretations of the results that could have a specific relevance to practitioners working on projects within organizations:

[1] The variable: 2) Executive support and project sponsorship is identified as a key factor with maximum driving power and high dependency. Additionally, its position and interconnections in the digraph illustrates its high extensive influence on the other variables in the model. In instances where a project suffers from inadequate executive support and project sponsorship we can conclude from the ISM analysis that a number of other potential linked factors could materialize on the project. This highlights the criticality of this factor and aligns with a number of studies that highlight the importance of appointing the right person for this fundamental role (Nixon 2012; Prosci 2012; Young 2005). Project managers need to ensure they are aware of these potential links in the event that their project suffers from poor project sponsorship or lack of support from the organization executive. In practice this means that having identified weaknesses in the exec support or sponsorship of the project, the project manager must address these areas quickly or suffer the consequences of carrying risk further along the project lifecycle and potentially increasing the impact on the project.

[2] The variables: 3) Project business case, 6) Size and complexity of project, 15) Training, 2) Executive support and project sponsorship and 5) Post mortem process, are identified in the MICMAC analysis as having the highest driving power and therefore, the highest influence on the other factors. If a project experiences failure due to any of these factors then due to the high driving influence of each of the variables, the project is likely to suffer from further problems due to related factors. In practice this means that project managers must be mindful of the impact that problems in any of these areas could potentially have on the project. Furthermore, due to the high impact of these factors, organizations could perhaps benefit from closely monitoring the status, quality and change management impact of key deliverables in these areas.

[3] The MICMAC analysis positions the majority of the failure factors in the Linkage quadrant of the model. As such they are described as being unstable. Linkage variables have strong dependency power and strong driving power. Action on these variables is likely to have a corresponding effect on other variables and feedback on themselves. These characteristics mean that if a project suffers from any one or more of the factors outlined in this study, then due to the large number of interconnections, further problems are likely to result. The implication for project managers is that they need to focus on associated risks if their project is identified as failing due to any one of the listed factors. This is key as projects rarely fail due to a single isolated factor disconnected from the other issues on the project.

[4] The variables: 1) Relationship between organization and external contractor, 4) Staff Performance, 10) Employee Resistance, 14) Staff turnover, are identified at the top level of the digraph, highlighting the significant dependence levels of these factors. These highest level dependent variables are also interconnected with each other thereby indicating that for e.g. poor staff performance can lead to employee resistance issues that in turn could lead to staff turnover issues. Project managers are advised to take note of the potential for increased levels of risk on the project if problems arise due to any of these factors.

[5] The digraph identifies the following variables: 6) Size and complexity of project, 7) Project Management and risk management, 9) Stakeholder communications, 11) Change management, 12) Planning as having multiple connections to each of the following top level variables: 1) Relationship between organization and external contractor, 4) Staff Performance, 10) 
Employee Resistance, 14) Staff turnover. This identifies the volatile nature of the relationships between these variables in that by virtue of the interconnections between each, they are highly correlated. In practice this means that a project that is impacted by one of these variables, is very likely to suffer from the other interrelated factors. For example, if 9) Stakeholder communications is established as a failure factor on a project, then by association: 1) Relationship between organization and external contractor, 4) Staff Performance, 10) Employee Resistance, 14) Staff turnover, could all potentially become causes of failure and need to be focused on by the project manager.

[6] Factor 6) Size and complexity of project has been shown in the literature to be a key factor in the failure of projects with a number of case studies highlighting its direct link to failure (Gauld 2007; Jones 2004; Jones 2006; Mitev 1996; Nawi et al. 2011; Verner and Abdullah 2012). This factor has a direct association in the digraph with two variables at the same level: 3) Business case and 7) Project management and risk management, i.e. it is a driver for both of these factors. In practice this means that where a project is defined as being large and complex, project managers and executives need to pay particular close attention to potential issues with 3) Business case and 7) Project management and risk management to ensure that these associated factors are not impacted. In reality this may mean that additional resources or specific controls or processes are put in place to concentrate on these areas. Specifically, these two related factors need to be assessed from the risk perspective as to the potential probability and impact of issues arising from the project being large and complex.

[7] The factor 13) Evaluation or pilot stage is shown in the digraph as a key driver for the following variables: 6) Size and complexity of project, 7) Project Management and risk management, 11) Change management, 12) Planning. In turn this factor is driven by 2) Executive support and sponsorship. These relationships highlight the key dependency that the establishment of an evaluation stage or running of a feasibility pilot can have on the factors in the next level of the digraph. In practice this means in instances where a poor evaluation is carried out or where an organization has chosen not to undertake any product evaluation or solution feasibility, a large number of potential problem areas could now become issues. The net effect of this is that organizations need to think very carefully on whether they can fully quantify the risk and therefore, impact on the project by not conducting any feasibility as an early lifecycle activity.

[8] The factor 5) Post mortem process is located as the bottom layer of the digraph and is listed in the MICMAC as having relatively low dependence power when compared to other factors within the analysis. This factor is solely linked to 2) Executive support and project sponsorship and 13) Evaluation or pilot stage. However, this factor is defined as having maximum driving power as shown in the MICMAC analysis with a maximum level of fifteen in this example. The net effect of this is a recognition of the importance and driving dependency of learning the lessons from failure and factoring these back into future initiatives within the organization.

[9] The factor 15) Training is listed in the MICMAC analysis as having very high driving power but relatively low dependence power. This factor has direct links with: 4) Staff Performance, 10) Employee Resistance, 14) Staff turnover. As such training has is shown to have a significant influence over these connected factors. Therefore, in instances where a project has experienced problems with training or the quality or quantity of training has been impacted through for e.g. budget or time constraints, there are associated potential issues relating to this factor that need to be taken account of and clearly addressed. 
[10] Practitioners may experience a scenario where one or more of the factors identified in this study are categorized as failing, but the project manager may have limited influence in terms of control of this specific area. Examples of this could be where a project manager has identified that 2) Executive support and project sponsorship is not being performed adequately. This could be perhaps due to the wrong person being appointed or a lack of commitment to the role. Another example could be where problems are identified as a direct result of 6) Size and complexity of project. In each of these instances although the practitioners may have limited influence over these factors, it is vital that the threats to the project are identified as part of the risk process in terms of their probability and impact on the project. The process of assessing threats should include the impact of the causal links between the factors as identified in this study.

\section{Conclusions}

The literature has explored the many and varied reasons for the failure of IS projects. However, as discussed earlier in this study, the detailed analysis and discussion of the relationships between failure factors has not featured highly within this genre of IS related studies. This study has utilized ISM as the methodology for the analysis and contextualizing of the key relationships between the factors. This is the key contribution of this research in that this approach has yielded further insight into the interrelationships between IS project failure factors.

This study has set out to deepen the analysis and understanding of the interrelationships of the many factors surrounding the failure of IS projects. Fifteen of the key IS failure factors were selected from the literature and processed through the various steps in the ISM methodology. The findings highlight the unstable nature of the selected failure actors in the context of their impact on each other and themselves. These results suggest a strong interrelationship between many of the listed factors and highlights the multi-dimensional nature of IS project failure. The digraph shown in figure 12 has identified the key failure factors associated with high levels of driving power and therefore, influence over other factors in the model. These are located at the lower level of the digraph. This is key, in that if any one or more of these factors is identified as failing within a project, due to their influence over other related factors, further issues may occur. The top level of the digraph denotes those factors that have the highest levels of dependency on the other factors in the model. In practice this means that these variables will be impacted if any of the linked variables lower in the model are subject to failure. These high dependent factors are identified need to be monitored closely in the event of any dependent factor problems.

This study is positioned as a further contribution to the understanding of IS project failure and the multidimensional nature of failure factor analysis. The results of this study can serve as a framework in the development of further research that has the potential to widen our understanding of how IS projects fail. Importantly, we present this study as a framework to provide organizations and academics alike with a structure to support the development of further research into the causal relationships and interdependencies of the key factors. Future study will extend the findings from this research to develop and refine a predictive framework for the development of an early warning signs predictive hypothesis.

\subsection{Limitations of Study}

The findings of this research are limited by the selection of a single specific methodology namely ISM. The limitation here is the inability to differentiate and compare the findings of a greater number of contrasting methodologies rather relying solely on ISM. Additionally, 
although the process followed in this study adheres to the steps as outlined in the ISM process and as such have an empirical element; the results have not been statistically validated. This research is also limited by its selection of IS failure factors in isolation from the literature view on the factors surrounding project success. Future studies are recommended to extend the ISM approach to include project success factors and also to align the work in this study with a specific project methodology such as PRINCE2 ${ }^{\circledR}$. Government IS project failure is a common occurrence and a more detailed analysis of the root causes via an ISM approach could yield useful results in terms of moving this areas of research forward. Additionally, it is recognized that the ISM process although structured and methodical is extremely time consuming and prone to human error. To mitigate these issues it is recommended that future studies look to develop a software solution to automate the ISM process and develop the required steps including the resulting MICMAC analysis.

\section{References}

Agarwal, A., \& Shankar, R. 2003. "On-line trust building in e-enabled supply chain.” Supply Chain Management: An International Journal, 4, 324-334.

Agarwal, A., Shankar, R., \& Tiwari, M. K. 2007. "Modeling agility of supply chain.” Industrial Marketing Management, 36 (4): 443-457.

Al-Ahmad, W., \& Al-Fagih, K. 2009. "A Taxonomy of an IT Project Failure: Root Causes." International Management Review, 5 (1): 93-104.

Avison, D., \& Wilson, D. 2002. "IT failure and the collapse of One. Tel." Proceedings of the IFIP $17^{\text {th }}$ World Computer Congress - TC8 Stream on Information Systems: The e-Business Challenge, 31-46

Barker, T., \& Frolick, M. 2003. "ERP Implementation Failure A Case Study.” Information Systems Management, Fall

BBC 2016a. Accessed on 01.01.2016. "Home Office criticized over $£ 830 \mathrm{~m}$ 'failed' borders scheme," http://www.bbc.co.uk/news/uk-34988913

BBC 2016b. "BBC was complacent over failed $£ 100 \mathrm{~m}$ IT project," http://www.bbc.co.uk/bbctrust/news/press_releases/2013/pwc_dmi.html,_Accessed on 01.01.2016.

Beynon-Davies, P. 1995. "Information systems failure: the case of the London Ambulance services Computer Aided Despatch project." European Journal of Information Systems, 4 (3): 171-184.

Bronte-Stuart, M. 2009. "Risk Estimation From Technology Project Failure." $4^{\text {th }}$ European Conference on Management of Technology Euro MOT 2009.

Brown, A., and Jones, M. 1998. "Doomed to Failure: Narratives of inevitability and conspiracy in a Failed IS Project.“ Organization Studies 19 (1): 73-88. 
Buchanan, D., Fitzgerald, L., Ketley, D., Gollop, R., Jones J.L., Lamont, SS., Neath, A., \& Whitby E. 2005. "No going back: A review of the literature on sustaining organizational change." International Journal of Management Reviews, 7 (3): 189-205.

Burnes, B. 2005. “Complexity theories and organizational change. "International Journal of Management Reviews, 7 (2): 73-90.

Bussen, W., \& Myers M 1997. "Executive Information System Failure: A New Zealand Case Study." Journal of Information Technology, 12 (2): 145-153.

Change Management Institute - (CMI). 2014, The Effective Change Manager: The Change Management Body of Knowledge (CMBoK), VIVID, Australia.

Chander, M., Jain, S.K., \& Shankar, R. 2013. "Modeling of information security management parameters in Indian organizations using ISM and MICMAC approach", Journal of Modelling in Management, 8 (2): 171 - 189.

Conboy, K. 2010. "Project Failure en Mass: A Study of Loose Budgetary Control in ISD Projects." European Journal of Information Systems, 8 (40): 1-14.

Conway, C.M., \& Limayem, M. 2011. "You want it when? How temporal dissonance in IT workers contributes to project failures." International Conference on Information Systems 2011, Shanghai.

Cullen, A.J., \& Taylor, M. 2009. "Critical success factors for B2B e-commerce use within the UK NHS pharmaceutical supply chain.” International Journal of Operations \& Production Management, 29 (11): 1156-1185.

Dwivedi, Y.K., Janssen, M., Slade, E.L., Rana, N.P., Weerakkody, V., Millard, J., Hidders, J., \& Snijders, D. 2016. Driving Innovation through Big Open Linked Data (BOLD): Exploring Antecedents using Interpretive Structural Modelling. Information Systems Frontiers (In Press).

Dwivedi, Y.K., Wastell, D., Laumer, S., Henriksen, H.Z., Myers, M.D., Bunker, D., Elbanna, A., Ravishankar, M.N., \& Srivastava, S.C. 2015. "Research on Information Systems Failures and Successes: Status Update and Future Directions." Information Systems Frontiers, 17 (1): 143-157.

Dwivedi, Y.K., Ravichandran, K., Williams, M.D., Miller, S., Lal, B., Antony, G.V., \& Kartik, M. 2013. IS/IT project failures: A review of the extant literature for deriving a taxonomy of failure factors. In Dwivedi et al. (eds.) Grand successes and failures in IT. Public and private sectors, Springer, Berlin, Heidelberg, 73-88.

Emam, K. El., \& Koru, A. 2008. "A Replicated Survey of IT Software Project Failures. Software," IEEE 25 (5): 84-90.

Ewusi-Mensah, K. 2003. Software development failures: anatomy of abandoned projects. The MIT Press, 45-64.

Ewusi-Mensah, K., \& Przasnyski, Z. 1995. "Learning from Abandoned Information systems development projects." Journal of Information Technology, 10: 3-14. 
Fenech, K., De Raffaele, C. 2013. "Overcoming ICT project failures - A practical perspective." World Congress on Computer and Information Technology, Sousse.

Fitzgerald, G., \& Russo, N.R. 2005. "The turnaround of the London ambulance service computer-aided dispatch system (LASCAD)". European Journal of Information Systems, 14 (3): 244-257.

Flowers, S. 1997. "Information systems failure: Identifying the critical failure factors." Failure and Lessons Learned in Information Technology Management, 1 (1): 19-29.

Gauld, R. 2007. "Public Sector Information System Failures: Lessons from a New Zealand hospital organization." Government Information Quarterly, 24: 102-114.

Goulielmos, M. 2005. "Applying the organizational failure diagnosis model to the study of information systems failure." Disaster Prevention and Management, 14 (3): 362-377.

Heeks, R. 2002. "Information Systems and Developing Countries: Failure, Success, and Local Improvisations." The Information Society, 18 (2): 101-112.

Hirschheim, R., Newman, M. 1988. "Information Systems and User Resistance: Theory and Practice." The Computer Journal, 31 (5): 398-408.

Hughes, D.L., Dwivedi, Y.K., Simintiras, A.C., \& Rana, N.P. 2015. Success and Failure of IS/IT Projects - A State of the Art Analysis and Future Directions, Springer, AG Switzerland.

Janes, F.R. 1988. "Interpretive structural modelling: a methodology for structuring complex issues." Transactions of the Institute of Measurement and Control, 10 (3): 145-154.

Jiang, J. J., Klein, G., \& Balloun, J. 1998. "Perceptions of system development failures." Information and Software Technology, 39 (14): 933-937.

Jones, C. 2004. "Software Project Management Practices: Failure Versus Success." The Journal of Defense Software Engineering October 5-9.

Jones, C. 2006. "Social and technical reasons for software project failures." CrossTalk, 19 (6): 4-9.

Kappelman, L.A., McKeeman, R., \& Zhang, L. 2006. "Early warning signs of IT project failure: The dominant dozen." Information Systems Management, 23 (4): 31-36.

Keider, S. 1974. "Why Projects Fail.” Datamation, 20 (12): 53-55.

Keil, M., Cule, P.E., Lyytinen, K., \& Schmidt, R. C. 1998. "A framework for identifying software project risks." Communications of the ACM, 41 (11): 76-83.

Kerzner H (2013) Project Management. A Systems Approach to Planning, Scheduling and Controlling, $5^{\text {th }}$ Edition, John Wiley and Sons, Hoboken, New Jersey. 
Lehtinen, TOA., Mäntylä, M.V., Vanhanen, J., Itkonen, J., \& Lassenius, C. 2014. "Perceived causes of software project failures - An analysis of their relationships." Information and Software Technology, 6 (6): 623-643.

Lemon, W.F., Liebowitz, J., Burn, J., \& Hackney, R. 2002. "Information systems project failure: A comparative study of two countries." Journal of Global Information Management, 10 (2): 28-39.

Lin, Y.M., \& Pan, X. 2011. "Study on risk scenarios of project failure based on Monte-Carlo simulation." 2011 IEEE 18th International Conference on Industrial Engineering and Engineering Management, IE and EM 2011, 1291-1295.

Linberg, K.R. 1999. "Software developer perceptions about software project failure: A case study." Journal of Systems and Software, 49, (2): 177-192.

Luthra, S., Kumar, V. \& Haleem., A. 2011. "Barriers to implement green supply chain management in automobile industry using interpretive structural modelling technique - An India perspective," Journal of Industrial Engineering and Management, 4 (2): 231-257.

Lyytinen, K., \& Hirschheim, R. 1987. "Information Systems Failures: A survey and Classification of the Empirical literature," Oxford surveys in information, 257-309.

Lyytinen, K., \& Robey, D. 1999. "Learning failure in information systems development." Information Systems Journal, 9 (2): 85-101.

McGrath, K. 2002. "The Golden Circle: a way of arguing and acting about technology in the London Ambulance Service.” European Journal of Information Systems, 11 (4): 251-266.

Mandal, A., \& Deshmukh, S. G. 1994. "Vendor selection using interpretive structural modelling (ISM)." International Journal of Operations \& Production Management, 14 (6): 5259.

Meade, L. M., \& Sarkis, J. 1999. "Analyzing organizational project alternatives for agile manufacturing processes: an analytical network approach." International Journal of Production Research 37 (2): 241-261.

Michie, S., \& West, M. 2004. "Managing people and performance: an evidence based framework applied to health service organizations." International Journal of Management Reviews, 5 (2): 91-111.

Mitev, N.N. 1996. "More than a failure?" The computerized reservation systems at French Railways. Information Technology \& People, 9 (4): 8-19.

Monteiro de Carvalho, M. 2014. "An investigation of the role of communication in IT projects", International Journal of Operations \& Production Management, 34 (1): 36 - 64.

Nawi, H.S.A., Rahman, A.A., \& Ibrahim, O. 2011. "Government's ICT project failure factors: A revisit." 2011 International Conference on Research and Innovation in Information Systems, Kuala Lumpur: 1-6. 
Nelson, R. 2007. "IT Project Management: infamous failures, classic mistakes and best practices." MIS Quarterly Executive, 6 (2): 67-68.

Newman, M., \& Sabherwal, R. 1996. "Determinants of Commitment to Information Systems Development: A Longitudinal Investigation.” MIS Quarterly, 20 (1): 23-54.

Nixon, P., Harrington, M., \& Parker, D. 2012. "Leadership performance is significant to project success or failure: a critical analysis." International Journal of Productivity and Performance Management, 61 (2): 204-216.

Nudurupati, S.S., Tebboune, S., \& Hardman, J. 2015. "Contemporary performance measurement and management (PMM) in digital economies." Production Planning \& Control, 27 (3): 226-235.

Pan, G., Hackney, R., \& Pan, S.L. 2008. "Information Systems implementation failure: Insights from prism.“ International Journal of Information Management, 28 (4): 259-269.

Pettigrew, A., \& Whipp, R. 1993. Managing Change for Competitive Success. Oxford: Black, $269-295$.

Perkins, T.K. 2006. "Knowledge: The core problem of project failure.” CrossTalk, 19 (6): 1315.

Philip, T., Schwabe, G., \& Ewusi-Mensah, K. 2009. "Critical issues of offshore software development project failures." In ICIS 2009 Proceedings - Thirtieth International Conference on Information Systems. Phoenix, AZ.

Pinto, J.K., \& Mantel, S.J. 1990. "The causes of project failure." IEEE Transactions on Engineering Management, 37 (4): 269-276.

Poulymenakou, A., \& Holmes, A. 1996. "A contingency framework for the investigation of information systems failure." European Journal of Information Systems, 5 (1): 34-46.

Prosci. 2012. Best Practices in Change Management. Prosci Benchmarking Report, Loveland: CO: Prosci®.

Purohit, J.K., Mittal, M.L., Mittal, S., \& Sharma M.K. 2016. "Interpretive structural modelingbased framework for mass customisation enablers: an Indian footwear case." Production Planning and Control, 1-13

Ravi, V., \& Shankar, R. 2005. "Analysis of interactions among the barriers of reverse logistics." Technological Forecasting and Social Change, 72 (8): 1011-1029.

Rob, M. 2003. "Project failures in small companies.” IEEE Software, 20 (6): 94-95.

Rockart, J.F. 1982. 'The changing role of the information systems executive: a critical success factors perspective", Sloan Management Review, 23 (1): 3-13.

Sage, A. P. 1977. Methodology for large-scale systems. McGraw-Hill College. 
Salimifard, K., Abbaszadeh, M. A., \& Ghorbanpur, A. 2010. "Interpretive structural modeling of critical success factors in banking process re-engineering." International Review of Business Research Papers, 6 (2): 95-103.

Samantra, C., Datta, S., Sankar Mahapatra, S., \& Ranjan, B. 2016. "Interpretive structural modelling of critical risk factors in software engineering project." Benchmarking: An International Journal, 23 (1): 2-24.

Sauer, C. (1993). Why Information Systems Fail: A Case Study Approach. Alfred Waller Ltd.

Sauer, C., Southon, G., \& Dampney, C. 1997. "Fit, failure, and the house of horrors: toward a configurational theory of IS project failure." Proceedings of the eighteenth International Conference on Information Systems ICIS Atlanta 349-366.

Saxena, J.P., \& Vrat, P. 1992. "Scenario building: a critical study of energy conservation in the Indian cement industry." Technological Forecasting and Social Change, 41 (2): 121-146.

Schmidt, R., Lyytinen, K., Keil, M., \& Cule, P. 2001. "Identifying software project risks: an international Delphi study." Journal of Management Information Systems, 17 (4): 5-36.

Scott, J., \& Vessey, I. 2000. "Implementing enterprise resource planning systems: the role of learning from failure." Information systems frontiers, 2 (2): 213-232.

Sharma, H.D., \& Gupta, A.D. 1995. "The objectives of waste management in India: a futures inquiry." Technological Forecasting and Social Change, 48 (3): 285-309.

Singh, M.D., Shankar, R., Narain, R., \& Agarwal, A. 2003. "An interpretive structural modeling of knowledge management in engineering industries." Journal of Advances in Management Research, 1 (1): 28-40.

Singh, R.K. 2011. "Developing the framework for coordination in supply chain of SMEs." Business Process Management Journal, 17 (4): 619-638.

Standing, C., Guilfoyle, A., Lin, C., \& Love, P.E.D. 2006. "The attribution of success and failure in IT projects." Industrial Management and Data Systems, 106 (8): 1148-1165.

Standish Group. 2013. CHAOS MANIFESTO Think Big Act Small. Boston. http://www.stansdishgroup.com

Talib, F., Rahman, Z., \& Qureshi, M. 2011, "Analysis of interaction among the barriers to total quality management implementation using interpretive structural modeling approach." Benchmarking: An International Journal 18 (4): 563-587.

Thakkar, J., Kanda, A., \& Deshmukh, S.G. 2007. "Evaluation of buyer-supplier relationships using an integrated mathematical approach of interpretive structural modeling (ISM) and graph theoretic matrix: the case study of Indian automotive SMEs". Journal of Manufacturing Technology Management, 19 (1): 92-124.

Tukel, OI., \& Rom W.O. 1998. "Analysis of the characteristics of projects in diverse industries." Journal of Operations Management, 16 (1): 43-61. 
Verner, J., Sampson, J., \& Cerpa, N. 2008. "What factors lead to software project failure?" Proceedings of the 2nd International Conference on Research Challenges in Information Science, RCIS 2008, 71-79.

Verner, J.M., \& Abdullah, L.M. 2012. "Exploratory case study research: Outsourced project failure." Information and Software Technology, 54 (8): 866-886.

Wallace, L., Keil. M., \& Rai, A. 2004. "Understanding software project risk: a cluster analysis." Information \& Management, 42 (1): 115-125.

Ward, J., \& Elvin, R. 1999. "A new framework for managing IT-enabled business change". Information Systems Journal, 9 (3): 197-221.

Warfield, J.N. 1974. "Developing subsystem matrices in structural modeling." Systems, Man and Cybernetics, IEEE Transactions on, 1: 74-80.

Warne, L., \& Hart, D. 1997. "Organizational politics and project failure: A case study of a large public sector project. Failure and Lessons Learned." Information Technology Management, 1 (1): 57-65.

Wiegel, W., \& Bamford, D. 2015. "The role of guanxi in buyer-supplier relationships in Chinese small-and medium-sized enterprises-a resource-based perspective". Production Planning \& Control, 26(4): 308-327.

Wiers, V. C. 2002. "A case study on the integration of APS and ERP in a steel processing plant." Production planning \& control, 13(6), 552-560.

Winklhofer, H. 2001. "Organizational change as a contributing factor to IS failure." Proceedings of the Hawaii International Conference on System Sciences, Hawaii

Yeo, K.T. 2002. "Critical failure factors in information system projects." International Journal of Project Management, 20 (3): 241-246.

Young, R. 2005. "An example of relevant IS research for top managers on IT project failure." ACIS 2005 Proceedings - 16th Australasian Conference on Information Systems. 